\title{
The Real-Time System for Perform Monitoring the Parameters of Photovoltaic Module
}

\author{
Davronov Shokhjakhon
}

\begin{abstract}
The development of solar energy has led to the construction of multiple many MW photovoltaic systems around the world. Wherever photovoltaic systems are built, it is first necessary to study the terrain, geographical location, weather conditions and various influencing factors on solar modules. To solve the above problems and study the influencing factors, the performance of photovoltaic modules in certain areas, specialized measuring devices are needed. The article describes a system for monitoring the parameters of the solar module, which measures air temperature, module temperature, solar radiation, wind speed, current-voltage characteristic, maximum power point (MPP), efficiency and fill factor (FF) with data stored in a computer. The system is based on a programmable microcontroller with a built-in analog-to-digital converter. The program code of the proposed system also has an algorithm for finding the maximum power point of the solar module. The system performs all measurements in real time and is convenient to use, since all parameters are measured automatically and are written to the computer in the form of tables. The paper examined the characteristics of alternative commercial measuring instruments for comparison with the proposed monitoring system. An electrical circuit for measuring currentvoltage characteristics and a circuit diagram of a monitoring system are proposed. Also shown are the measurement results in the form of graphs obtained with the device in real climatic conditions. In general, the developed monitoring system based on microcontrollers and additional digital sensors has a predominantly low cost of $\$ 72$ and is easy to manufacture.
\end{abstract}

Keywords: maximum power point; algorithm; software; I-V characteristic; fill factor; efficiency; monitoring; ADC; $P V$ panel; solar energy; measurement; solar radiation.

\section{INTRODUCTION}

Experiments in solar energy is an important part of this industry, since they make it possible to evaluate the performance and efficiency of using a particular technology under specific conditions. Instead of manual measuring methods, systems based on microcontrollers came that can solve problems of accuracy in measurements. The main advantage of such systems is their computing power, multitasking, accuracy and flexibility in measurements. As you know, the air temperature and relative humidity, wind speed, solar radiation, number of sunny days per year differ based on location and these parameters must be taken into account when installing solar panels.

Revised Manuscript Received on April 25, 2020.

* Correspondence Author

Davronov Shokhjakhon*, doctoral student, Department of labor training, Karshi state university, Karshi, Uzbekistan. Email: shoxjahon94@gmail.com

(C) The Authors. Published by Blue Eyes Intelligence Engineering and Sciences Publication (BEIESP). This is an open access article under the CC BY-NC-ND license (http://creativecommons.org/licenses/by-nc$\underline{\mathrm{nd} / 4.0 / \text { ) }}$
Measurement of the characteristics affecting the performance of photovoltaic panels is an urgent task, as this Using such parameters as solar radiation, azimuth, and the angle of is constantly fluctuating due to changes in solar radiation [2]. inclination of solar panels, the efficiency of installing solar power plants in the areas is calculated [1]. Being dependent on environmental changes, the power of photovoltaic panels will allow studying the parameters of the solar panel and drawing conclusions which of them are suitable for operation in certain places. There are different types of measurements of the parameters of photovoltaic panels. One of the widespread is the traditional method of measurement in which all measurements are carried out manually using multimeters and various analog temperature meters [3]. But today, in measuring processes are increasingly being used embedded systems and real-time systems [4, 5]. Using traditional methods of measurement of parameters is difficult to achieve accurate and real results, unlike automated measurement systems. Microcontroller-based systems are widespread and are used to monitor parameters [6], and in particular, to conduct research and obtain data from solar power plants and the environment [7-11]. Such systems allow the use of full control, strategies and can significantly increase the energy efficiency of solar installations [12-16]. Because programmable microcontroller devices have a high processing speed and multi-tasking processes, and functional advantages include the presence of digital ports, pulse width modulation, analog-to-digital converter, universal asynchronous receiver/transmitter (UART) used for data transfer via the serial ports of the computer and programming environment.

Data acquisition devices, known as data loggers, are very expensive and require special software for use [17]. Inexpensive technological solutions in the process measurement renewable energy systems are considered to be largely desirable, compared with the average or expensive alternatives, if it is expected to equal the effectiveness of each option [5].

There are many devices to measure the parameters of solar panels. For example, the device I-V400w - Electrical network meter, made in Italy, measures such parameters as [18]:

- IV curve (I-V Curve test) of photovoltaic panels.

- Temperature of photovoltaic panels $\left(-20 \ldots 100^{\circ} \mathrm{C}\right)$

- Radiation intensity (1 ... $100 \mathrm{mV})$,

- The cost is - $4200 \$$.

The PROVA 210 solar module analyzer device, whose manufacturer is Taiwan China, measures such parameters as [19]:

- I-V solar curve test

Published By:

Blue Eyes Intelligence Engineering 


\section{The Real-Time System for Perform Monitoring the Parameters of Photovoltaic Module}

- Maximum voltage (Vmaxp) at Pmax,

- Maximum current (Imaxp) at Pmax,

- Open circuit voltage (Vopen),

- Short circuit current (Ishort),

- Maximum measurement parameters $60 \mathrm{v}, 12 \mathrm{a}$

- Cost 940 \$.

The above data acquisition systems allow monitoring the parameters of photovoltaic systems, which include the measurement, acquisition and processing of environmental data. But such systems highly dependent on expensive sensors and microcontrollers [20].

Multiple studies have shown [3-5, 21-23] that the development of low-cost measuring devices is possible and feasible to perform certain tasks. Seema Suryavanshi et al. [21] propose a microcontroller based method in which the load and the battery are connected to the photocell through a relay. The microcontroller determines the power consumption of the load and thereby controls two photocells to connect them to the load or to the battery. Work H.E. Gad and Hisham E. Gad [20], proposes the development of a new temperature data collection system for solar applications. The main advantage of the device is its flexibility and simplicity of measuring sensors and the method of recording data. Also in the work of Nyoman Sugiartha et al. [3], a developed Arduino-based data acquisition device for monitoring the parameters of a solar PV system is described. The data acquisition device, based on the Arduino Mega board with the ATmega 2560 microcontroller, was developed, manufactured and tested on the SHS test bench. The data acquisition device developed by the author constantly monitors the parameters of the photovoltaic system, such as voltage, current, panel temperature, ambient temperature and relative humidity, and writes them to a CSV file with a sampling frequency of 10 minutes. In the work of Wai Mar Myint Aung et al. [22], they developed a system for monitoring the data of photovoltaic panels, which operates based on Arduino UNO and ATmega 328p is installed in its base and monitors such parameters as temperature, illumination, current and voltage, all the data obtained in measurements are displayed on the LCD. In the work of P.N. Kuznetsov et al. [23], a device for remote monitoring of parameters of a solar power station is provided. The work presents a structural diagram of the device, showing the connection and the purpose of its main functional elements. The circuit is based on the ATmega 328p microcontroller, which transfers the processed data from the sensors to the server by sending a GET request using the Wiznet Ethernet controller - W5100.

\section{METHODOLOGY}

\section{A. Instrument hardware}

Development of a measuring device for the parameters of photovoltaic module (MDPP) was carried out according to the following steps:

1. Development of hardware for the measuring device based on microcontrollers and sensors.

2. Development environment and preparation of libraries for interaction with external sensors of the device.

3. Writing software for the microcontroller of the device to ensure the functionality of the entire system.
4. Development of the user interface and recording the received data in the form of tables.

5. Testing and calibration of the device for operability and accuracy of calculations.

The device presented in the work runs on the Arduino platform, which is based on the ATmega 2560 microcontroller from ATMEL [24]. The Arduino Mega with the ATmega 2560 microcontroller chip uses the core to process signals from 54 digital I/O ports, 16 analog inputs, and a $256 \mathrm{~KB}$ flash drive. To determine the temperature and relative humidity of the environment, a digital DHT 22 sensor is used with power from 3.3 to 6 volts DC, humidity range from 0 to $100 \%$ accuracy $\pm 2 \%$, temperature range from -40 to $80^{\circ} \mathrm{C}$ resolution $0.1^{\circ} \mathrm{C}$ accuracy $\pm 0.5^{\circ} \mathrm{C}$ [25]. To measure the temperature of the photovoltaic panel, a digital sensor DS18B20 was used to, the operating voltage of which is up to 6 volts, the temperature range from -55 to $125^{\circ} \mathrm{C}$, accuracy $\pm 0.5^{\circ} \mathrm{C}$ [26]. External digital measuring sensors are used to measure wind speed and solar radiation. The part of the device that measures the I-V characteristic of the PV was developed independently and was tested under real conditions, the circuit is shown in fig. 1 . The I-V characteristic measuring unit works as follows: When the computer's COM port is opened, the microcontroller sends a signal to a specific digital port at which four-digit binary counters are triggered, through which the signals are sent to the keys and controlled by the load of the PV using resistors. The resulting current and voltage values are taken in the form of digital signals, processed by the program and converted to the desired values for recording.

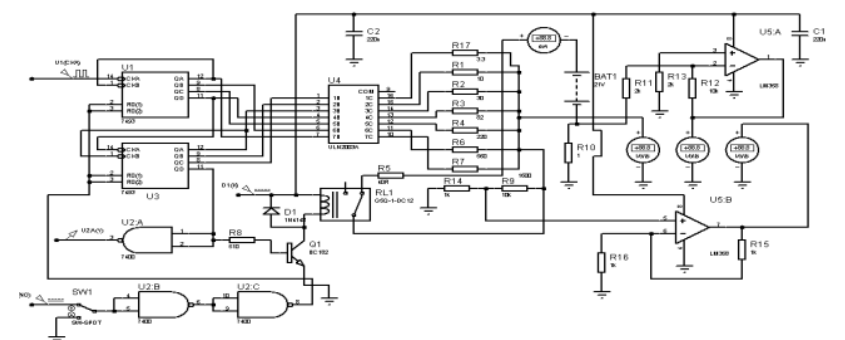

Fig. 1. Scheme of the current device for measuring the I$\mathrm{V}$ characteristics.

The fig. 2 shows that all the sensors interact only with the microcontroller, which in turn connected to the computer. The microcontroller performs all basic operations, such as requesting and processing signals from sensors. The received signals from all digital elements are converted to the appropriate values (for example: watt $/ \mathrm{m}^{2}$, $\mathrm{m} / \mathrm{s}, \%$ and ${ }^{\circ} \mathrm{C}$ ) and then sent to the computer for recording and storage via serial ports. In real time measurement and storage of data performed.

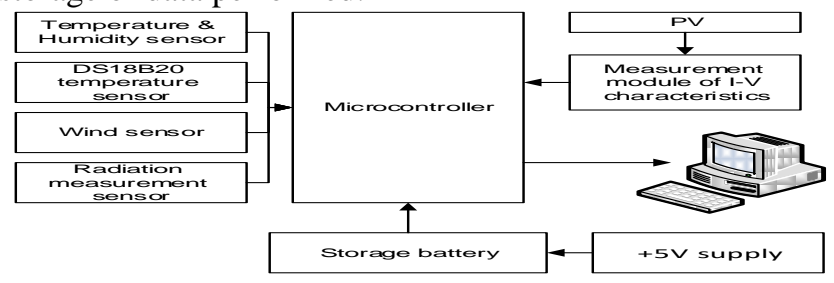

Fig. 2. Schematic diagram of the interaction of sensors with the microcontroller of the measuring device

Published By:

Blue Eyes Intelligence Engineering \& Sciences Publication 
The device is autonomous because internal batteries power it, which in turn are powered by the PV connected to the device, the device circuit is designed so that during measurements of the I-V characteristic the PV stops charging the batteries of the device and all the power goes to measure the volt-ampere characteristics. This method is due to the fact that this monitoring system is an experimental measuring device and all tests were carried out on a PV with a maximum power of 9.5 watts.

To measure the temperature on the solar panels, we used the DS18B20 digital temperature sensor, which works as follows, the MC receives signals from the DS18B20 temperature sensor through a digital input/output port and converts them to degrees Celsius using a special software library. To measure environmental characteristics, the digital module DHT22 is used, which measures temperature and relative humidity, which also generates digital signals, which, after entering the MC, are converted to the desired values using software libraries.

\section{B. Instrument software}

To develop software for the monitoring system, the Arduino IDE development environment was used, as shown in fig. 3. The main libraries used in the program code are libraries of temperature sensors:

\#include $<$ OneWire.h $>$

\#include $<$ DallasTemperature.h $>$

\#include $<$ DHT.h $>$

Since these libraries were used, there was no need to recognize and process signals transmitted by sensors. All processing was performed by the above libraries.

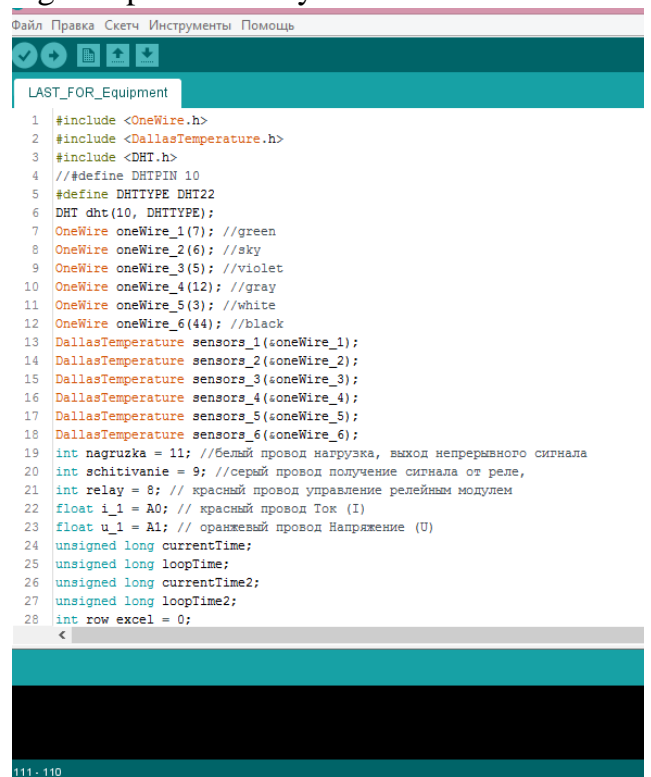

Fig. 3. Software development environment for the Arduino platform

To measure the temperature and relative humidity of the environment, the DHT22 sensor first queries and records the received data into variables. It is necessary to declare data types of variables as float to prevent measurement errors, after assigning data to variables, it will be possible to print them on an LCD screen or send them to a computer for recording, which is done by the code below:

air_humidity = dht.readHumidity ();

air_temperature $=$ dht.readTemperature ();

Serial.print (air_humidity);

\section{Serial.print (air_temperature);}

To measure the temperature of the module, the program sends a command to the temperature measurement request and assigns them to the variables. After that, the received data can be printed or transferred to a computer using the following commands:

sensors_1.requestTemperatures ();

Serial.print (sensors_1.getTempCByIndex (0));

The level of solar radiation is determined by a pyranometer. The pyranometer sensor sends signals in analog form to the signal amplification module to increase accuracy, after which it is transmitted to the microcontroller through an analog-to-digital converter (ADC). To measure the value of solar radiation, it is necessary to read the signals from the analog port using special commands and assign them to a variable, after convert to the desired coefficient to calculate the efficiency of the photovoltaic module.

$$
\begin{aligned}
& \text { float } p \_1=\text { analogRead }\left(p i r \_1\right) ; \\
& \text { float } p i r \_11=\left(\left(p \_1 * 5\right) * 9.5\right) / 10 ;
\end{aligned}
$$

The main task of the measuring device is to measure the volt-ampere characteristic and search for the maximum power point. Below is the part of the program code in which the conditional expression for the search for the maximum power point is performed, sorting through the $I-V$ characteristics of each measurement point.

$$
\begin{aligned}
& \text { I_in }=i \_11 ; \\
& U \_i n=\left(u \_11 * 3\right) / 100 ; \\
& I V \_c h a r=I \_i n * U \_i n ; \\
& \text { if }\left(I V \_c h a r>M P P\right)\{ \\
& M P P=I V \_c h a r ; \\
& I \_m p=I \_i n ; \\
& U \_m p=U \_i n ; \\
& \}
\end{aligned}
$$

The program code prescribed in the MC operates in accordance with the algorithm for measuring the current voltage characteristics and finding the maximum power point with the calculation of the efficiency and FF of the photoelectric module (fig. 4). The algorithm measures the power at 256 points and takes 10 seconds of time for a complete measurement cycle. During the cycle of power measurements, the algorithm writes to the database each value with subsequent comparison. In comparisons, if the measured power is greater than the previous one, then its value is recorded in a separate variable as $P_{m p}$, the value in the variable is updated every time there is a value exceeding that recorded in the variable. Measurements stop when the cycle is completely completed at 256 points and these power values are written to the * .xlsx file of the computer in the form of tables using the PLX-DAQ program. When all measurements end on the final 256th row of the table, all parameters of the solar cell and the values of the influencing factors are displayed. 


\section{The Real-Time System for Perform Monitoring the Parameters of Photovoltaic Module}

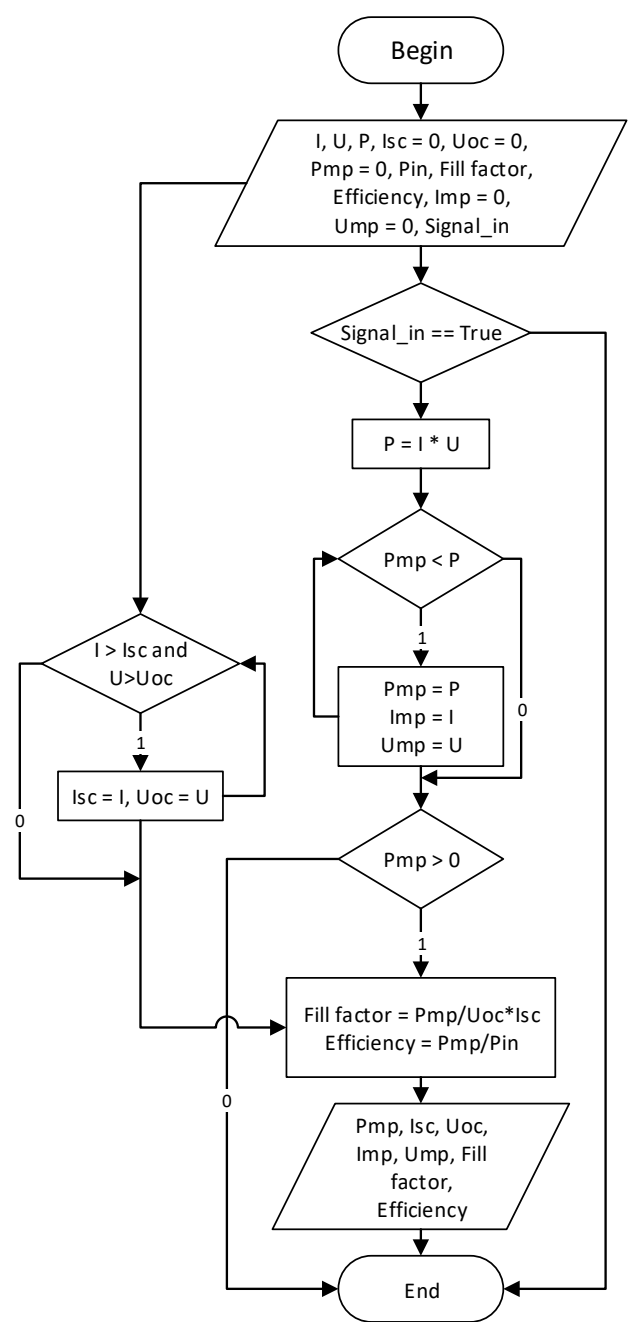

Fig. 4. The block diagram of the software algorithm with the search for the maximum power point.

The received data from the monitoring system is written to the database in the form of tables using the PLX-DAQ program that works with spreadsheets. The PLX-DAQ receives data from the computer's serial port when connected to the system. In the following (fig. 5, insert), a program window is displayed through which it is connected to the MC and data is recorded in the tables. As can be seen in fig. 5 in the program settings, you can specify the desired port to which the device is connected and indicate the port data exchange rate.

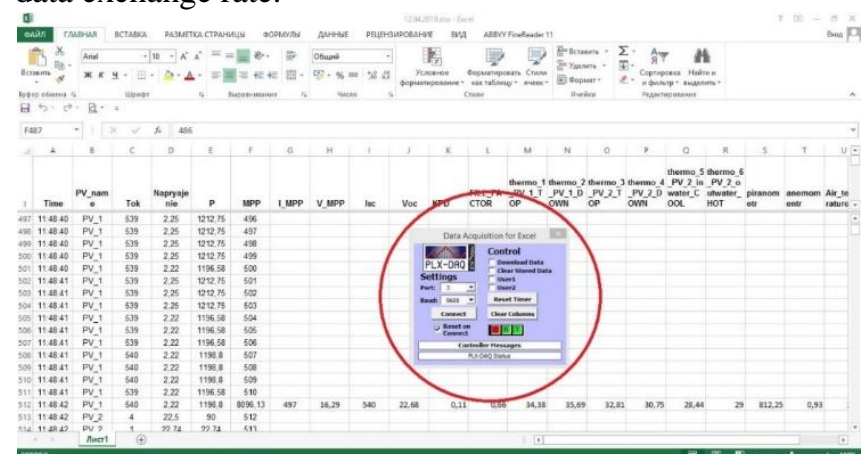

Fig. 5. Display all data on excel using the program PLXDAQ

The developed monitoring system was tested in real conditions. Fig. 6 shows the developed device for parallel measurement of the parameters of the photoelectric and solar thermal converter module, on which the measuring device for monitoring the parameters of PV is installed. The system was tested on a CIGS module with passport data of 9.5 W maximum power, $22.9 \mathrm{~V}$ open circuit voltage and 0.60 A short circuit current.

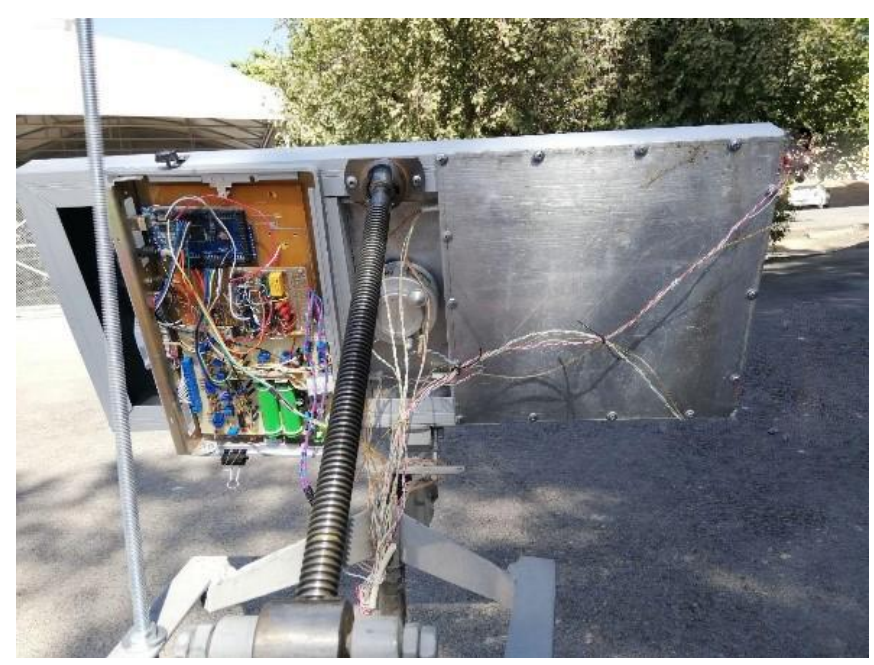

Fig. 6. Photo of the monitoring system with the installation on which it was used

The developed monitoring system measures the temperature and relative humidity of the environment, the temperature of the back of the photovoltaic module, I-V characteristic, the point of maximum power, and when the radiation sensor is connected, it is able to measure incoming solar radiation and wind speeds. From the processed data, the system software extracts the necessary values, calculates the maximum power, efficiency, and fill factor of the photovoltaic module

This monitoring system was developed using only widely available and inexpensive modules and sensors (Table 1). The developed device differs from the analogues in this work in that it has advanced functions and can measure parameters that affect the performance of PV that were not considered in other works. In other parameter monitoring systems, the authors measured environmental characteristics, panel temperature, current, and voltage. But it should be noted that when monitoring the parameters of solar cells, you need to pay attention to the volt-ampere characteristic of the solar cells and the point of maximum power. Since these factors are fundamental for determining the efficiency of the modules. It is also necessary to measure the incoming solar radiation per $\mathrm{m}^{2}$ in order to calculate the efficiency and Fill factor of the PV.

Table- I: The list of used parts in the project

\begin{tabular}{|l|c|}
\hline \multicolumn{1}{|c|}{ Name } & Price \\
\hline Microcontroller Arduino Mega & $38.50 \$$ \\
\hline Device for measuring I-V characteristic & $12 \$$ \\
\hline Temperature and relative humidity sensor DHT 22 & $4 \$$ \\
\hline DS18B20 temperature sensor & $2 \$$ \\
\hline Batteries & $12 \$$ \\
\hline Battery Charger overall & $4 \$$ \\
\hline \multicolumn{2}{|c|}{. } \\
\hline
\end{tabular}

\section{RESULTS AND DISCUSSIONS}

Below are the test results of the monitoring system, fig. 7 shows a graph of the change in air temperature and the temperature of the PV.

Published By:

Blue Eyes Intelligence Engineering \& Sciences Publication 
Monitoring of temperature parameters has an important role since the temperature of a solar panel affects its conversion characteristics, which decrease at a high temperature of the panel [27]. Also fig. 8 shows a graph of the change in solar radiation during the day with points of maximum power of the PV. This schedule was built as the incoming solar radiation directly affects the generated power of the PV. Fig. 9 shows all the output parameters of the CIGS PV module that were measured during the test process. From the graphs provided, you can see that the real-time monitoring system determines all the influencing factors on the PV modules. To observe the dynamics of all parameters on one graph, their immeasurable values are used (conventional unit), which is calculated according to the following formula: $n^{\prime}=\frac{n}{n_{\max }}$, where $\mathrm{n}$ is the value of the measured parameter, $\mathrm{n}_{\max }$ is the maximum value of the measured parameter [28].

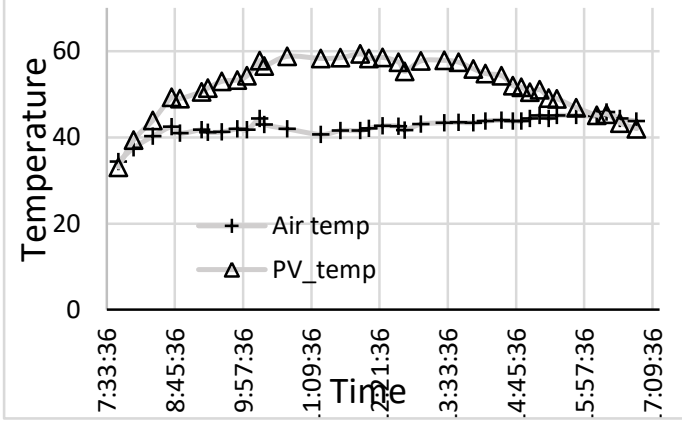

Fig. 7. Tracking the temperature of the air and the temperature of the PV during the day (08/03/2019)

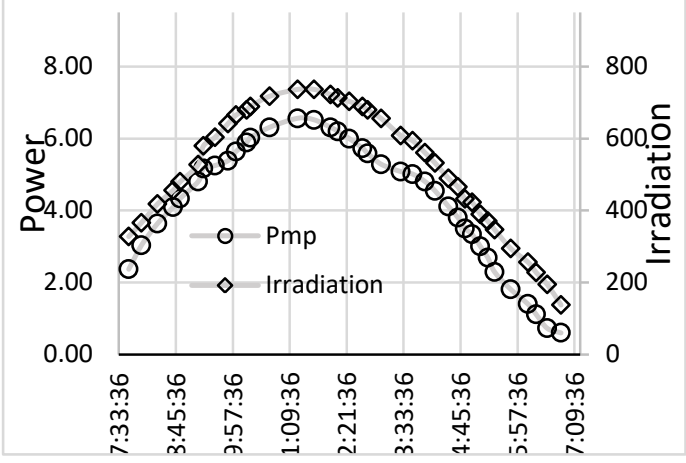

Fig. 8. Change in solar radiation during the day and comparison with the points of maximum power of the PV (08/03/2019, the angle of inclination is $51^{\circ}$ and the azimuth angle is $-34^{\circ}$ ).

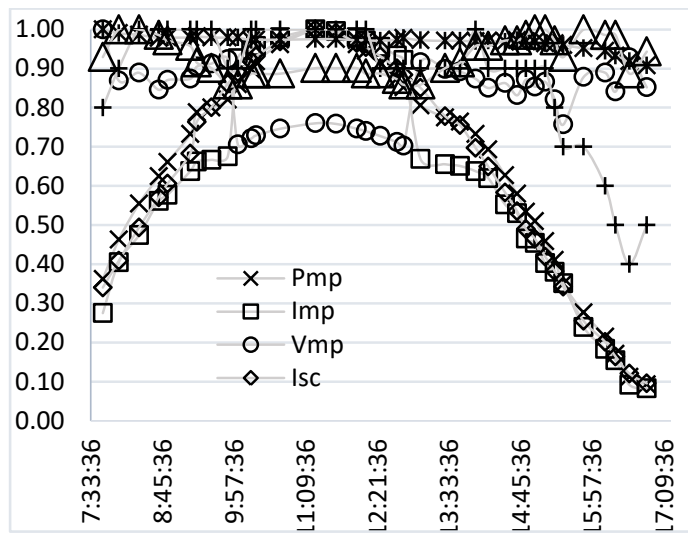

Fig. 9. Graphs of all the basic characteristics of PV (08/03/2019)
The table below shows the values of the graphs shown in Figure 9. In the table, the values of the maximum power point, current at the maximum power point, voltage at the maximum power point, short circuit current, and open circuit voltage are shown relative to time.

Table- II: Output parameters of CIGS PV module

\begin{tabular}{|c|c|c|c|c|c|}
\hline Time & $\mathbf{P}_{\mathbf{m p}}$ & $\mathbf{I}_{\mathbf{m p}}$ & $\mathbf{V}_{\mathbf{m p}}$ & $\mathbf{I}_{\mathbf{s c}}$ & $\mathbf{V}_{\mathbf{~} \mathbf{}}$ \\
\hline 7:46:06 & 2,37 & 0,123 & 19,29 & 0,164 & 21,84 \\
\hline $8: 02: 09$ & 3,03 & 0,181 & 16,77 & 0,197 & 21,63 \\
\hline $8: 22: 27$ & 3,63 & 0,212 & 17,16 & 0,238 & 21,54 \\
\hline $8: 42: 19$ & 4,09 & 0,251 & 16,32 & 0,275 & 21,36 \\
\hline $8: 51: 06$ & 4,33 & 0,258 & 16,8 & 0,292 & 21,39 \\
\hline $9: 20: 33$ & 5,17 & 0,296 & 17,46 & 0,368 & 21,45 \\
\hline $9: 35: 14$ & 5,24 & 0,298 & 17,61 & 0,386 & 21,39 \\
\hline $9: 51: 38$ & 5,38 & 0,302 & 17,82 & 0,415 & 21,39 \\
\hline $10: 01: 47$ & 5,63 & 0,414 & 13,62 & 0,429 & 21,39 \\
\hline $10: 15: 14$ & 5,88 & 0,423 & 13,92 & 0,443 & 21,24 \\
\hline $10: 44: 15$ & 6,3 & 0,438 & 14,4 & 0,467 & 21,27 \\
\hline $11: 19: 41$ & 6,55 & 0,447 & 14,67 & 0,482 & 21,3 \\
\hline $11: 40: 25$ & 6,51 & 0,445 & 14,64 & 0,478 & 21,3 \\
\hline $12: 01: 17$ & 6,3 & 0,438 & 14,4 & 0,465 & 21,24 \\
\hline $12: 24: 55$ & 5,99 & 0,427 & 14,04 & 0,449 & 21,21 \\
\hline $12: 41: 40$ & 5,72 & 0,417 & 13,74 & 0,434 & 21,27 \\
\hline $13: 05: 17$ & 5,28 & 0,299 & 17,67 & 0,410 & 21,24 \\
\hline $13: 30: 01$ & 5,08 & 0,293 & 17,34 & 0,375 & 21,21 \\
\hline $14: 00: 39$ & 4,80 & 0,285 & 16,86 & 0,336 & 21,18 \\
\hline $14: 30: 21$ & 4,11 & 0,247 & 16,65 & 0,281 & 21,15 \\
\hline $15: 10: 37$ & 3,0 & 0,180 & 16,71 & 0,202 & 21,06 \\
\hline $15: 28: 47$ & 2,29 & 0,157 & 14,61 & 0,165 & 20,97 \\
\hline $16: 10: 55$ & 1,4 & 0,082 & 17,16 & 0,097 & 20,64 \\
\hline $16: 35: 18$ & 0,73 & 0,041 & 17,91 & 0,058 & 20,07 \\
\hline $16: 52: 40$ & 0,6 & 0,037 & 16,44 & 0,046 & 19,83 \\
\hline
\end{tabular}

\section{CONCLUSION}

This article has developed a system for performing monitor the parameters of PV modules. A circuit diagram of a monitoring system and an electrical circuit of a device for measuring the current-voltage characteristics are proposed. An algorithm searching for the maximum power point of the PV module functioned in the proposed monitoring system is also proposed. The measuring device, developed on the basis of the ATmega2560 microcontroller with a built-in analog-to-digital converter, has been tested in real climatic conditions. The monitoring system measures the external that influencing factors on the PV modules. The software of the microcontroller, after performing all measurements of the influencing factors and the $\mathrm{I}-\mathrm{V}$ characteristic, converts the received signals to the necessary values. In the process of operation of the microcontroller software, multitasking is used, the advantage of which allows processing data and sending it to a computer at the same time for writing to the database using the PLX-DAQ program. Hence, the proposed monitoring system is distinguished by productivity, versatility and relatively inexpensive components for implementation than industrial designs with similar functionality. 


\section{The Real-Time System for Perform Monitoring the Parameters of Photovoltaic Module}

\section{REFERENCES}

1. В. S. Andrutsky, S. M. Ponomarenko. Эффективность солнечных электростанций на территории Украинь [The efficiency of solar power plants in Ukraine]. // XV All-Ukrainian scientific-practical conference of students, graduate students and young scientists "Theoretical and applied problems of physics, mathematics and computer science", May 25-27, 2017, Kiev. "POLYTEKHNIKA", 2017. - pp. 72-75.

2. J. Prasanth Ram, N. Rajasekar. A new global maximum power point tracking technique for solar photovoltaic (PV) system under partial shading conditions (PSC). Energy xxx (2016) pp. 1-14. http://dx.doi.org/10.1016/j.energy.2016.10.084

3. Nyoman Sugiarth, I Made Sugina, I Dewa Gede Agus Tri Putra, Made Alwin Indraswara. Development of an Arduino-based Data Acquisition Device for Monitoring Solar PV System Parameters. International Conference on Science and Technology (ICST 2018). Atlantis Highlights in Engineering (AHE), volume 1, pp. 995-999. https://dx.doi.org/10.2991/icst-18.2018.201

4. S. B. Chavana, P. A. Kadamb, and S. R. Sawant. Embedded Web Server for Monitoring Environmental Parameters. // ISSN 00204412, Instruments and Experimental Techniques, 2009, Vol. 52, No. 6, pp. 784-787.

5. Luis J. Claros-Marfil, J. Francisco Padial, Benito Lauret. A new and inexpensive open source data acquisition and controller for solar research: Application to a water-flow glazing. // Renewable Energy 92 (2016) 450-61. http://dx.doi.org/10.1016/j.renene.2016.02.037

6. A.J. Davies, Microprocessors and Their Use in Physics, Vol. 47 of Advances in Electronics and Electron Physics, Academic Press, 1978, pp. 51-121.

7. R. Mukaro, X.F. Carelse, A microcontroller-based data acquisition system for solar radiation and environmental monitoring, Instrum. Meas. IEEE Trans. 48 (6) (1999) pp. 1232-1238.

8. M. Benghanem, A. Arab, K. Mukadam, Data acquisition system for photovoltaic water pumps, Renew. Energy 17 (3) (1999) pp. 385-396.

9. E. Koutroulis, K. Kalaitzakis, Development of an integrated dataacquisition system for renewable energy sources systems monitoring, Renew. Energy $28 \quad$ (1) (2003) pp. 139-152. http://dx.doi.org/10.1016/S0960-1481(01)00197-5

10. S. Rosiek, F. Batlles, A microcontroller-based data-acquisition system for meteorological station monitoring, Energy Convers. Manag. 49 (12) (2008) $\quad$ pp. 3746-3754. http://dx.doi.org/10.1016/j.enconman.2008.05.029

11. M. Benghanem, Measurement of meteorological data based on wireless data acquisition system monitoring, Appl. Energy 86 (12) (2009) pp.

2651-2660. http://dx.doi.org/10.1016/j.apenergy.2009.03.026

12. G. Johnson, A microprocessor based solar controller, in: Decision and Control Including the 16th Symposium on Adaptive Processes and a Special Symposium on Fuzzy Set Theory and Applications, 1977 IEEE Conference, 1977, pp. 336-340.

13. R. Moen, Solar energy management system, in: Decision and Control Including the Symposium on Adaptive Processes, 1979 18th IEEE Conference, 2, 1979, pp. 917-919.

14. S. Kotob, M. Salman, S. Ayyash, M. Farhat, Low cost microprocessor based optimal controller for solar cooling systems, in: Decision and Control, 1983. The 22nd IEEE Conference, 1983, pp. 958-963.

15. G. Muralidhar, J. Nagaraju, S. Mohan, A solar controller with a microprocessor based temperature monitor, in: W. Bloss, F. Pfisterer (Eds.), Advances in Solar Energy Technology, Pergamon, Oxford, 1988, pp. 2824-2828.

16. L.M. Nhut, Y.C. Park, A study on automatic optimal operation of a pump for solar domestic hot water system, Sol. Energy 98 Part C (0) (2013) pp. 448-457.

17. M. Fuentes, M.Vivar, J.M.Burgos, J.Aguilera, J.A.Vacas. Design of an accurate, low-cost autonomous data logger for PV system monitoring using Arduino ${ }^{\text {TM }}$ that complies with IEC standards. // Solar Energy Materials \& Solar Cells $130 \quad$ (2014) pp. 529-543. http://dx.doi.org/10.1016/j.solmat.2014.08.008

18. I-V400w - HT Italia Electrical Networks Meter. // https://novapribor.ru/catalog/elektroizmeritelnye_pribory/izmeriteli_pa rametrov_elektricheskikh_setey/izmeritel_parametrov_elektricheskikh _setey_ht_italia_i_v400w/ (accessed 09/14/2019)
19. PROVA 210 solar module analyzer. // http://www.tes.com.tw/en/product_detail.asp?seq=286 (accessed 09/14/2019)

20. H.E. Gad, Hisham E. Gad. Development of a new temperature data acquisition system for solar energy applications. // Renewable Energy 74 (2015) pp. 337-343. http://dx.doi.org/10.1016/j.renene.2014.08.006

21. Seema Suryavanshi, Shruti Tiwari (IEEE member), Shiv Kumar. Online monitoring and controlling of the PV generated solar power through AVR microcontroller ATmega16. // 2017 2nd International Conference for Convergence in Technology (I2CT), pp. 169-173. http://dx.doi.org/10.1109/I2CT.2017.8226114

22. Wai Mar Myint Aung, Yadanar Win, Nay Win Zaw. Implementation of Solar Photovoltaic Data Monitoring System. // International Journal of Science, Engineering and Technology Research (IJSETR) Volume 7, Issue 8, August 2018, pp. 592-596, ISSN: 2278 -7798

23. P.N. Kuznetsov, N.V. Lyamina, L.Yu. Yuferev. Ustroystvo udalennogo monitoringa parametrov solnechnoy elektrostantsii [Device for remote monitoring of solar power plant parameters]. // Geliotekhnika, 2019, Volume 55, No. 3, pp. 249-257.

24. ATmega2560 [Electronic resource]. - Atmel Public Information Corporation https://www.microchip.com/wwwproducts/en/ATMEGA2560 (accessed 09/15/2019)

25. Humidity and temperature sensor DHT22 (Digital Humidity Temperature) https://iarduino.ru/lib/DHT22.pdf (accessed 09/15/2019)

26. DS18B20 Programmable Resolution 1-Wire Digital Thermometer https://datasheets.maximintegrated.com/en/ds/2812.pdf $\quad$ (accessed 09/15/2019)

27. A. Komilov. Improving the Design of a Photoconverter with a Heat Sink Using Mathematical Simulation. // ISSN 0003701X, Applied Solar Energy, 2011, Vol. 47, No. 3, pp. 229-233. http://dx.doi.org/10.3103/S0003701X11030108

28. A. Komilov, Voprosy uprosheniya metodov testirovaniya fotopreobrazovateley na osnove $\mathrm{Cu}$ (In, Ga) Se $\mathrm{Se}_{2}$ (CIGS). Chast 1. Osnovi dlya matematicheskogo modelirovaniya volt-ampernyx xarakteristik (VAX) [Simplification of testing methods for photoconverters based on $\mathrm{Cu}$ (In, Ga) $\mathrm{Se}_{2}$ (CIGS). Part 1. Basics for mathematical modeling of current-voltage characteristics (CVC)] // Geliotekhnika, 2017, No. 1, pp. 5-9.

\section{AUTHORS PROFILE}

Davronov Shokhjakhon was born on July 8, 1994 in Karshi, Kashkadarya region, Uzbekistan. In 2011, he entered the Tashkent University of Information Technologies. Research in the field of I-V characteristics and improving performance of PV modules. He began his career at the department of software engineering, Tashkent University of Information Technologies Karshi branch from 2017-2018. In 2018 he entered doctoral studies at the Karshi State University. Email: shoxjahon94@gmail.com, Phone: +998912577222 